\title{
Elective applied research course: A motivational approach to enhance learning
}

\author{
Maha Othman ${ }^{* 1,2}$, Wilma M. Hopman ${ }^{3,4}$, Valerie Sawyer ${ }^{1}$, Calvin Kerr ${ }^{1}$ \\ ${ }^{1}$ School of Baccalaureate Nursing, St. Lawrence College, Kingston, Ontario, Canada \\ ${ }^{2}$ Department of Biomedical and Molecular Sciences, Queens's University, Kingston, Ontario, Canada \\ ${ }^{3}$ Clinical Research Center, KGH, Kingston, Ontario, Canada \\ ${ }^{4}$ Department of Public Health Sciences, Queen's University, Kingston, Ontario, Canada
}

Received: October 16, 2015

DOI: $10.5430 /$ jnep.v6n4p9
Accepted: November 25, 2015 Online Published: November 30, 2015

URL: http://dx.doi.org/10.5430/jnep.v6n4p9

\begin{abstract}
Nursing programs and educators have long recognized the need to prepare students for evidence based nursing practice, and for being well-informed about nursing research. Literature indicates course-based undergraduate research experiences are linked to pursuing graduate degrees, and/or continuing with research pursuits. There is limited published evidence on how nursing research should be taught. The objective of this study is to evaluate a novel course-based model -developed at our institution for integration of practical research in undergraduate years. This model was designed to help students appreciate the steps, and efforts involved in generating and completing research studies they are often required to critically analyze. We describe the model and report the results of a study designed to evaluate the elective course outcomes based on a 4-year experience. The study is composed of: a retrospective comparative analysis of final grades in relation to core research courses, a structured online survey to capture students' perspectives and experiences and thematic analysis of course feedback. Results showed while there was no significant difference in the final courses' grades of the two mandatory research courses between students who took the elective and those who did not, there were significant differences between the years and a trend towards a significant effect of the research course in one of the years. Survey data and thematic analysis document the course benefits and show $100 \%$ of students recommend the course. Examining education models such as this can support the evolving needs of nursing students and enhance the quality of nursing graduates.
\end{abstract}

Key Words: Nursing research, Undergraduate research, Nursing curriculum, Course feedback

\section{INTRODUCTION}

\subsection{Research and undergraduate nursing education}

It is well established that the best nursing practice is based on scientific evidence. Evidence-informed practice supports sound decision-making and contributes to continuous learning. Nursing programs and educators have long recognized the need to prepare their students for evidence based nurs- ing practice, and for being well informed about nursing research ${ }^{[1]}$ Literature also indicates that course-based undergraduate research experiences are linked to pursuing graduate degrees and enhancing perspectives of, and/or continuing with research. ${ }^{[2]}$ Accordingly, nursing students in many undergraduate nursing programs are often required to take one or more courses in nursing research. The goal is to help them better understand and also utilize quantitative and qualitative

\footnotetext{
*Correspondence: Maha Othman; Email: mothman@sl.on.ca; Address: School of Baccalaureate Nursing, St. Lawrence College, Kingston, Ontario, Canada.
} 
research evidence. ${ }^{[3,4]}$ However, there is limited published evidence on how nursing research should be taught. This makes the practice of teaching nursing students; the evidencebased practice in fact lacking the actual evidence. ${ }^{[5]}$

While nursing students are generally taught the importance of research with respect to evidence-based practice and how to critique research articles, they may lack exposure to practical research (real world learning) that complements their theoretical learning. This is mainly related to the busy curriculum and also the limited time and resources.

Using an elective course, we recently developed a model for integrating practical research into the undergraduate program to expose students to the steps and efforts involved in generating and completing research studies.

In this report, we describe this undergraduate research model in detail and report the results of a study designed to evaluate the course's outcomes based on a 4-year experience. We highlight the strengths and values and we discuss challenges that are associated with the long-term delivery of this course. Examining models such as this can contribute towards a curriculum that suits the evolving needs of our students and also enhances the quality of our graduates.

\subsection{Research within St. Lawrence College (SLC) Bache- lor of Science in Nursing $(\mathrm{BScN})$ program}

The $\mathrm{BScN}$ program offered at SLC is a four year program offered in collaboration with Laurentian University. The program offers three research-based courses as posted on SLC website (2015); ${ }^{[6]}$ two courses in year 3 and one in year 4. Course map and evaluations are detailed in Figure 1. Apart from the university of Alberta Honor degree program, ${ }^{[7]}$ in most other Canadian programs the practical and laboratory exposure is limited or non-existent.

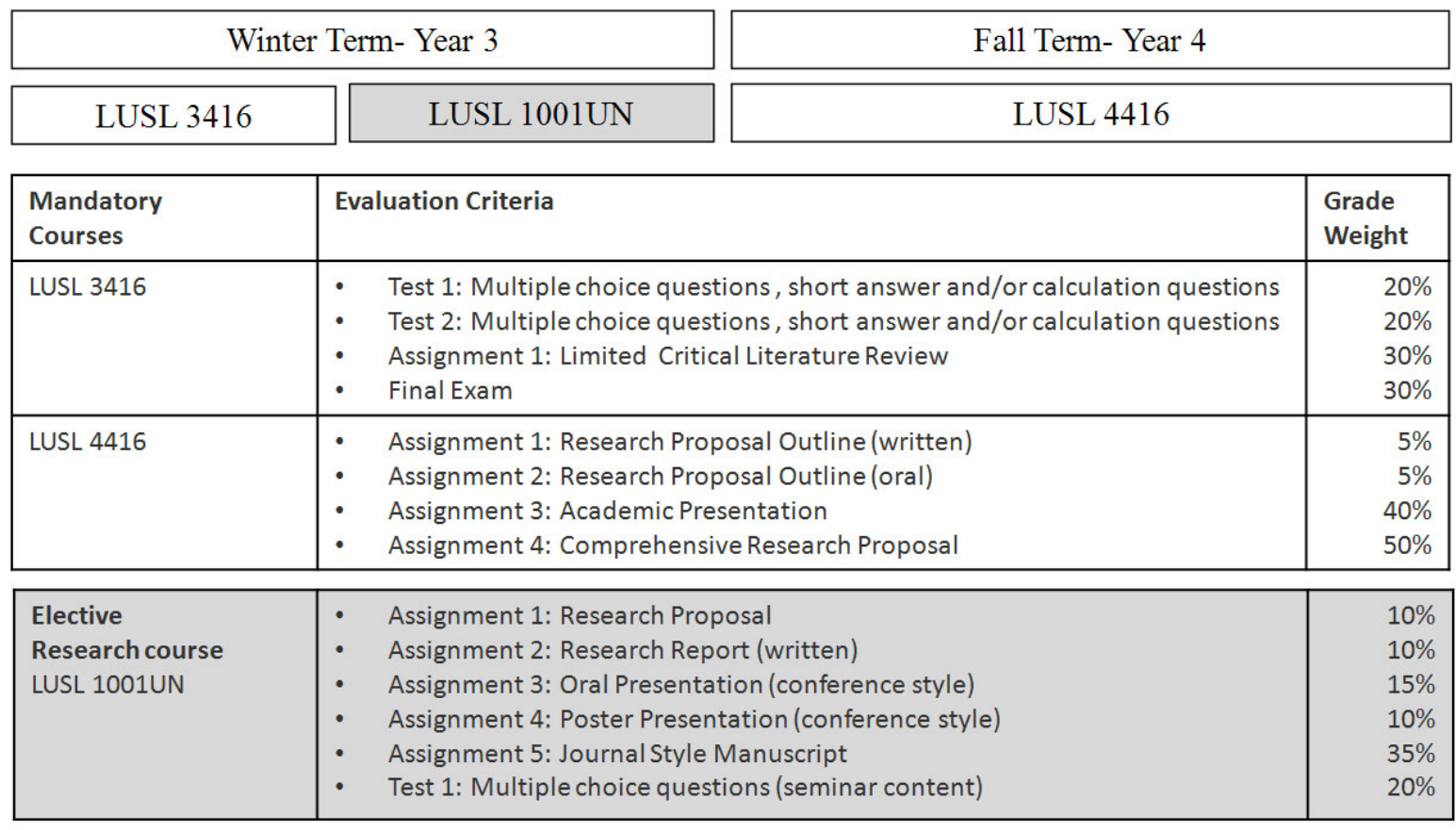

Figure 1. SLC BScN program's research course map and requirements

\subsection{The SLC model}

The practical research/ education model (LUSL1001UN) was introduced in winter 2011 as an elective course for the third year of BScN students. The course professor coaches students during every step of the course millstones (see Figure 2) to complete small-scale, student-led research projects. Each student's project includes a completion of literature review followed by formulation of a research question, writing a research proposal, conduction of an exploratory/investigative quantitative or qualitative study, performing data analysis using appropriate statistical methods, and drawing a conclusion. ${ }^{[8]}$ Students present their data publically at open poster and oral abstract symposia on campus. Examples of projects' titles, abstracts, and posters/oral presentations are available upon request.

The students also receive instructions regarding basic statistics, how to write a proposal, how to design a conference poster, how to design and deliver an effective oral presentation, and how to write a manuscript following author guidelines for publication in selected journals. In addition to this 
extensive coaching, a number of seminars run by specialized guest speakers to cover important, and seasoned topics in research such as ethics in human research, animal research and clinical trials are provided throughout the term.

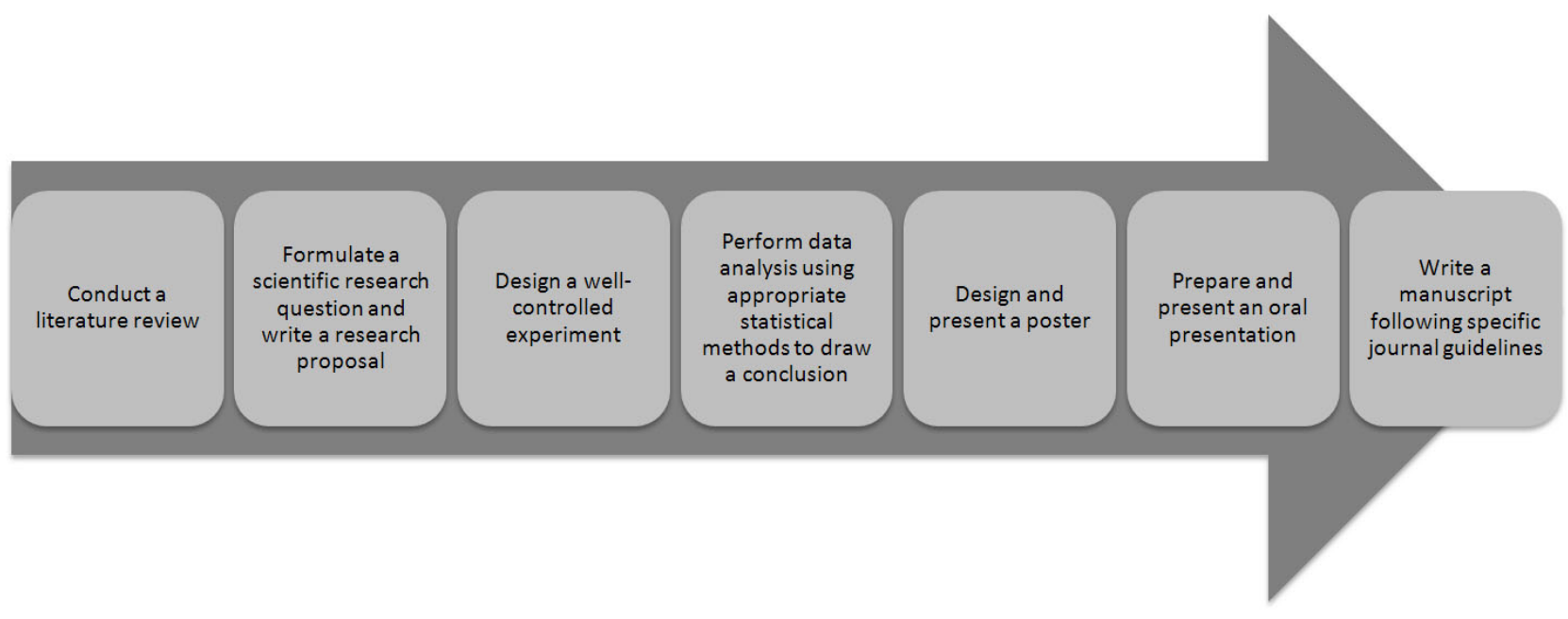

Figure 2. Research elective course milestones

LUSL1001UN was delivered for the past four years as a onesemester course, to a total of 48 students. While students' evaluations through the course milestones/assignments, together with students' annual course feedback have demonstrated that course objectives were being achieved, the impact of this learning experience on the performance of these students in the regular undergraduate research courses or post graduation has not been evaluated. Hence the study presented hereby.

\section{MeTHOD}

\subsection{Study outline}

The purpose of this study was to investigate the impact the elective course had beyond its ends in views. The study was specifically designed to: a) assess students' perspectives after completing the course and/or post graduation; b) investigate students' performance in the concurrent and subsequent core research courses.

The study had three components: prospective evaluation of a structured online questionnaire; a retrospective quantitative comparative analysis of students' grades/performances in two required core research courses delivered in the $\mathrm{BScN}$ program and a thematic analysis of comments included in course feedback over four years.

\subsection{Course data collection and analysis}

Following ethics approval, SLC course grades were obtained for all students in two required research course-one concurrent (LUSL3416) and one subsequent (LUSL4416) to the elective course. Figure 2 depicts the research course map at the SLC BScN program showing the schedule and distribution of research courses and also the courses' requirements/evaluations. Using student $t$-test, grades in the two required courses LUSL3416 and 4416 for the 48 students who completed the LUSL1001UN research elective between 2011-2014 were compared to LUSL3416 (190 students) and 4416 (187 students) who did not take the course. Two-way ANOVA and linear regression analysis were used to test the predictive effect of the elective course on each of the required courses per year and to compare years.

\subsection{The questionnaire}

Twenty-three questions were constructed using surveygizmo ${ }^{\circledR}$. Open boxes were included for comments. The questionnaire was administered between November 2014 and February 2015 and was sent to students via college email. Questions addressed the following points: whether the student already graduated or is a current student; whether the student included the course on their resume and/or if the course had any impact on post-graduation hiring; students' perspectives of the impact of the course on learning in other courses; the setting/type of their current practice; current understanding/evaluation/critique of research studies; and the use of knowledge/skills gained through this course. The questions also examined the student's current involvement in research, their motivation to pursue future graduate studies, and whether they would recommend the course to other students.

\subsection{Thematic analysis}

To perform thematic analysis, information from students' course feedback over 4 years were transcribed, key quotes 
were highlighted, categorized, and sorted according to emerging themes.

\subsection{Statistical analysis}

Descriptive statistics, student $t$-test, one-way ANOVA with Tukey's post-hoc testing, two-way ANOVA, and linear regression analysis were used. $P$ values $\leq .05$ were considered statistically significant. For each of the two courses, one-way ANOVA was performed to determine if there was an effect of year. Independent samples $t$-test was used to determine if there was a difference by whether or not students took the elective course. Two-way ANOVA was performed to see if there was an effect of year, course, and year $\times$ course. By examining this interaction of year $\times$ course, a course effect in some years, but not others, could be revealed. Linear regression analysis was performed to verify the outcome of ANOVA.

\section{Results}

Based on student $t$ test, there were no significant differences in the final grades for the required research-based courses between those who took the elective course and those who did not in any of the years 2011-2014 (see Figure 3). There was a highly significant between-year difference based on the one-way ANOVA in both courses. Post-hoc tests showed that grades in 2011 differed from grades in 2012 but not in the other two years; grades in 2012 differed from all of the other 3 years; and grades in both 2013 and 2014 differed from those in 2012. Looking at the interaction as tested in the two-way ANOVA, the research course falls just short of statistical significance $(P=.056)$ in year 2012 suggesting a potential effect in one of the years. This effect was also noted in the linear regression $(P=.055)$. This effect was related to the subsequent required research course. These latter data suggest the possibility that the elective course has value in enhancing learning in future research courses.

Questionnaire data are highlighted in Figure 4 (A-F). 11/48 (30\%) of students responded to the survey. $82 \%$ were currently in 4 th year and $18 \%$ were graduates. $45 \%$ have referred to the course in their resume and/or reported the course helped them in obtaining employment. 91\% strongly agreed or agreed that the course helped them better understand/evaluate or critique research. $100 \%$ felt the knowledge and experience they gained in this course enhanced their learning in other courses. $71 \%$ strongly agreed or agreed the course motivated them to purse graduate studies. $100 \%$ recommended the course to other students.
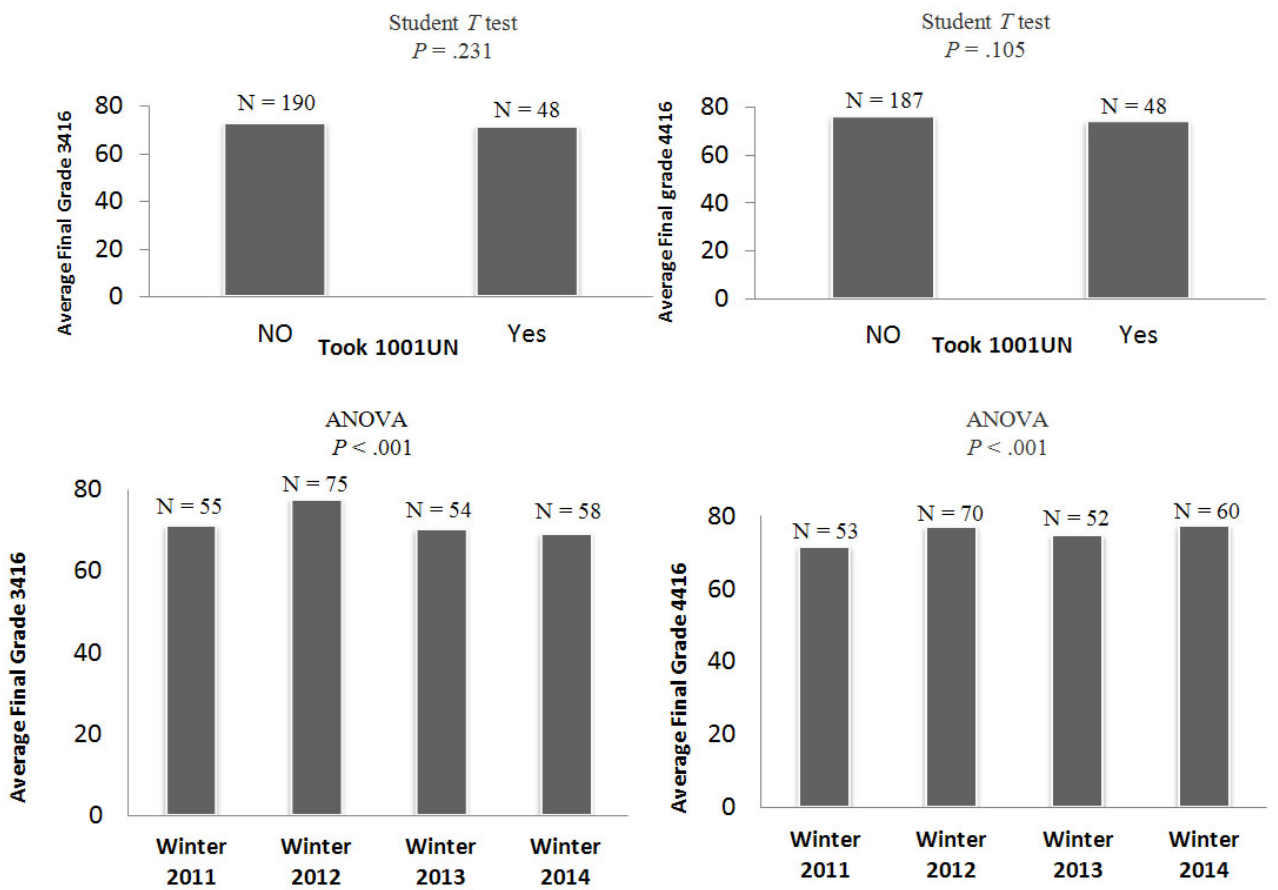

Figure 3. Comparative analysis on performance in two core courses

In analyzing students' course feedback comments over 4 years of course delivery, four themes emerged: quality coaching and interactive learning, enjoyable learning experience, 1. enthusiasm for teaching and support, positive recommendations. Detailed students' comments are provided in Table 1. 
A

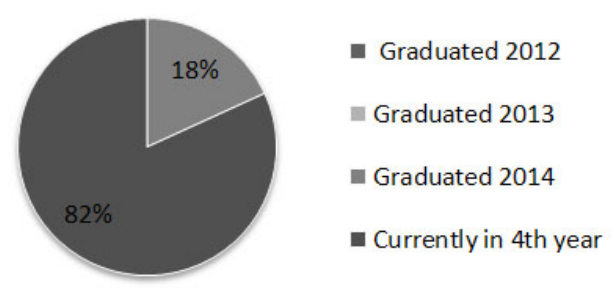

Q: Graduated or current student?

C

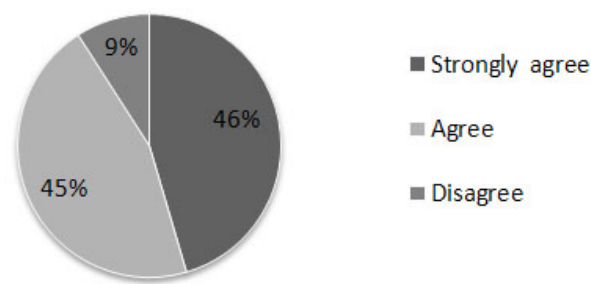

Q: I feel I better understand how to evaluate/critique research studies after taking this class.

E

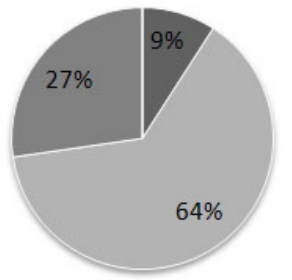

Q: Participation in this class motivated me to pursue graduate studies.
B

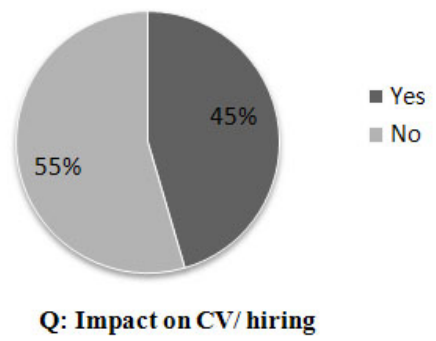

D

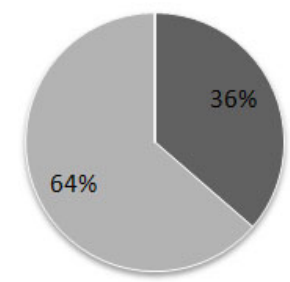

Q: The knowledge and experience I gained in this course enhanced my learning in other courses.

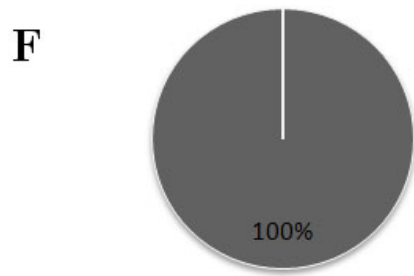

Q: I would recommend this class to other BScN students.

Figure 4. Questionnaire data

\section{Discussion AND CONCLUSION}

In this report, we describe a 4-year experience of a newly integrated research model in the undergraduate years of the $\mathrm{BScN}$ in one nursing program offered in Ontario, Canada.

Today's learners are clearly different than the past with respect to their needs, perspectives, and expectations. There is ample evidence in literature that today's nursing students have various and evolving needs. ${ }^{[9-14]}$ However, a gap in knowledge remains on how to best supplement nursing curricula with research and on to the identification of the best methods for teaching nursing research. ${ }^{[15,16]}$

Students in different undergraduate programs may have difficulty in understanding the research theory taught, particularly when practical applications are not emphasized or experienced.$^{[17,18]}$ Literature shows that listening to students' views and opinion of how they can be best taught can have valuable outcome. ${ }^{[19,20]}$

A close look to the two research courses (LUSL3416 and
4416) being offered in the $\mathrm{BScN}$ program at St. Lawrence College (see Figure 1), one can see that the literature review component overlaps between 3416 and the elective course and that the research proposal overlaps between the elective and 4416. The LUSL4416 builds on LUSL3416 and complements it. However, the elective course LU1001UN provides a global picture of how to conduct research from posing a research question till writing a manuscript for publication. The novelty and strength of the elective course lies in the practical application and the actual implementation of a study, which does not currently exist in any of the two research courses. While the three research courses share a core-learning objective, which is the understanding of research and its value, the approach for teaching/learning in LUSL1001UN is drastically different because of the actual implementation of a small-scale research study.

It is important to note that in LUSL4416, formulation of a research proposal and presenting it inside the classroom is the course' main assignment. 
Table 1. Thematic analysis-4 years students' course feedback

\begin{tabular}{|c|c|}
\hline Themes & Students Response \\
\hline \multirow{10}{*}{ Quality coaching and Interactive learning } & prof explained things well \\
\hline & great assistance in developing the first research study \\
\hline & enjoyed feedback given by professor to show strength and potential \\
\hline & very encouraging during presentations \\
\hline & received constructive feedback $\times 2$ \\
\hline & assisting with time management and ensure we are up to speed \\
\hline & relatable to other classes and valuable to nursing \\
\hline & hands on experience in research \\
\hline & positive atmosphere always \\
\hline & allows full understanding of what it takes to develop a research project \\
\hline \multirow{18}{*}{ Enjoyable learning experience } & enjoyed coming to class and doing the work \\
\hline & enjoyed teaching style \\
\hline & pleasure taking this course \\
\hline & amazing class \\
\hline & learned a lot, had fun and many new experiences \\
\hline & great course, interesting and fun \\
\hline & course is perfect \\
\hline & learning is fun and applicable \\
\hline & my favorite class in all 3 years in this program \\
\hline & great course \\
\hline & received positive/constructive feedback $\times 2$ \\
\hline & positive and inviting classroom \\
\hline & I feel confident in developing questionnaires \\
\hline & guest speakers were fantastic \\
\hline & best elective taken in 3 years $\times 2$ \\
\hline & enjoyed the course, hope it continues \\
\hline & positive learning environment \\
\hline & most interesting course in the whole year \\
\hline \multirow{19}{*}{ Enthusiasm for teaching and support } & prof very passionate about course and students \\
\hline & prof always available \\
\hline & great response to emails $\times 2$ \\
\hline & prof very supportive \\
\hline & prof has great enthusiasm/passion $\times 7$ \\
\hline & prof has exceptional interest in student success \\
\hline & prof's enthusiasm is excellent \\
\hline & prof. consistently seeking opportunities for students \\
\hline & appreciated all support, help and encouragement \\
\hline & prof worked hard \\
\hline & prof very helpful \\
\hline & Great/excellent/amazing/perfect/knowledgeable/understanding prof $\times 9$ \\
\hline & always there to help \\
\hline & excellent guidance $\times 3$ \\
\hline & ready and eager to help \\
\hline & genuinely care about students \\
\hline & best teacher I have had at SLC \\
\hline & shinning passion for research and teaching \\
\hline & cares about every student and works hard to help them \\
\hline \multirow{14}{*}{ Positive recommendations } & should be offered as a full time course \\
\hline & extension of program/ course \\
\hline & should be a requirement of the $\mathrm{BScN}$ program \\
\hline & it would be beneficial to have this as a full year course in third year \\
\hline & quality of assignment would benefit from more time \\
\hline & keep trying to make this a full year course \\
\hline & need more time to expand project \\
\hline & would be beneficial if class is one full year \\
\hline & a year long is beneficial to the studies \\
\hline & make this a full year/honors BScN \\
\hline & recommend to all students \\
\hline & whole year \\
\hline & year long course \\
\hline & have it run over longer period \\
\hline
\end{tabular}


For the elective course LUSL1001UN, a research proposal is an earlier assignment on which all other course assignments/milestones will build on; including the poster presentation of preliminary data from the research study, oral presentation when the research study is completed, written research report and finally writing a manuscript following journal specific author guidelines. This makes the elective course a more in-depth with more holistic approach helping students to learn the various steps of the real world research. We recognize that the elective course is ambitious and could be construed as graduate level expectations. However, the authors are aware of a closely similar model that exists in the Life Science Program at Queen's university. ${ }^{[21]}$

The LUSL1001UN course complements the theory taught in other courses with a practical approach that helps students live the real world experience in a small scale. This was evident from the thematic analysis of students' feedback over 4 years. Overall, the course provides a motivational approach for learning and enjoyable small scale exposure to the real world learning that may support future professional practice. Apart from one isolated comment requesting more detailed rubric and guidelines for assignments, there were no negative comments about the course.

While the students' grade analysis did not show that students who took the course performed better in other research course, this objective analysis was only based on final grades and did not examine grades on specific assignments components such as writing proposal (written/oral outlines) or literature review as shown in Figure 2. The potential content overlap between the three research courses could have also contributed to these results. Despite this, statistical analyses have revealed a potential impact of the course on final grades in one of the years as shown by a trend towards significance. However, given the small sample size, examining a larger cohort of student is likely to clarify and confirm this finding.

The significant differences in grades in between the years in both courses LUSL1346 and 4416, shown in the study are interesting. Possible hypotheses to explain this, could be the varying nature of the student group in each year, the change in the professors assigned to teach these course and/or the modification of course assignments which does take place from a year to year. A consistency in implementing a course would be valuable for an objective assessment of the outcomes over the years.

There is ample evidence from literature that engaging students in more authentic and real word experiences in the content and practices of their studies via undergraduate research has numerous benefits. Students improve their research and writing skills, promote creativity and alternative ways of thinking; stimulate intellectual curiosity and sharpen their ability to analyze, interpret, and synthesize together with experiencing collaboration. The benefits as well as the challenges of implementing undergraduate research have been extensively discussed. ${ }^{[22-26]}$

It is important to note that some nursing degree programs involve research as a mandatory element in the final year. In Canada, the University of Alberta (2015) offers one such program: the $\mathrm{BScN}$ Honor. This program provides the same clinical preparation as the regular $\mathrm{BScN}$ program, as well as research project conducted in the final year under supervision of a nurse faculty. Students explore topics related to nursing knowledge development and practice and work closely with a faculty supervisor to develop a research proposal and to conduct the research via two nursing courses. Students write a project report, and present their research results publically. Apart from this unique program, to our knowledge, the undergraduate LUSL1001UN course/model is one of a kind within nursing programs across Canadian universities/colleges and may be a step towards motivating nursing programs to examine/consider a similar model on larger scale.

We acknowledge the limitation of the LUSL1001UN course such as: resources available to support the research projects including support personnel; the short time frame for conducting projects (one semester); serving only small number of students; and the cost of supplies to run lab experiments needed for some projects. We also acknowledge the limitation of the study presented in this report to evaluate the course outcomes: only final grades were evaluated; detailed course assignments grades were not available for comparative analysis; as well as the small number of questionnaire participants. Despite of these limitations, the results particularly fortified by the thematic analysis of the 4 years course feedback, indicate there is merit in considering this type of students' learning opportunity. Larger scale examination of this and/or similar models together with studying further the logistics of implementation remain valuable for integrating practical research into nursing curricula.

In conclusion, over the past 4 years students have emphasized the strengths of the course at many levels and $100 \%$ of survey respondents recommended this course to other nursing students. Accordingly, we recommend the continuation of the course as an elective course while examining further the feasibility of integrating this as a regular two-semester course and/or an Honor's program. The elective course could also be developed into a graduate certificate that can be offered to $\mathrm{BScN}$ graduates. 


\section{ACKNOWLEDGEMENTS}

The authors would like to acknowledge the applied research department at St Lawrence College for funding the study. We would also like to thank Dr. Nancy Sears, professor and president of the College of Nurses of Ontario (CNO), Canada

\section{REFERENCES}

[1] Ciliska D. Educating for evidence-based practice. Journal of Professional Nursing. 2005; 21(6): 345-350. PMid:16311229 http: //dx.doi.org/10.1016/j.profnurs.2005.10.008

[2] Corwin LA, Graham MJ, Dolan EL. Modeling course-based undergraduate research experiences: An agenda for future research and evaluation. CBE Life Sciences Education. 2015; 14(1). http: $/ / \mathrm{dx}$.doi.org/10.1187/cbe.14-10-0167

[3] Grace JT, D'Aoust R. Evidence-based program requirements evaluation of statistics as a required course. Nursing Education Perspectives 2006; 27(1): 28-33. PMid:16613129

[4] Stranahan SD. Sequence of research and statistics courses and student outcomes. Western Journal of Nursing Research. 1995; 17(6): 695699. http://dx.doi.org/10.1177/019394599501700609

[5] Hagen B, Awosoga O, Kellett P, et al. Evaluation of undergraduate nursing students' attitudes towards statistics courses, before and after a course in applied statistics. Nurse Education Today. 2013; 33(9): 949-55. PMid:23206330 http://dx.doi.org/10.1016/j.nedt . 2012.11 .005

[6] St. Lawrence College, Bachelor of Science in Nursing (BScN). [cited 2015 Oct 17]. Available from: https://www. stlawrencecolleg e.ca/programs-and-courses/full-time/programs/a_m/b achelor-of-science-in-nursing-bscn/kingston/

[7] University of Alberta. Faculty of Nursing. [cited 2015 Oct 17] Available from: https://uofa.ualberta.ca/nursing/progr ams/undergraduate-programs-and-their-admissions-r equirements/honors-program

[8] Othman M. Integrating Practical Research in the Undergraduate Nursing Curriculum: A Motivational Approach to Enhance Learning 34th Annual Conference-Transforming our Learning Experiences. Queen's University, St. Lawrence College, and Royal Military College. 2014.

[9] Duane BT, Satre ME. Utilizing constructivism learning theory in collaborative testing as a creative strategy to promote essential nursing skills. Nurse Education Today. 2014; 34(1): 31-4. PMid:23608232 http://dx.doi.org/10.1016/j.nedt.2013.03.005

[10] Kantar LD. Assessment and instruction to promote higher order thinking in nursing students. Nurse Education Today. 2014; 34(5): 789-94. PMid:24035312 http://dx.doi.org/10.1016/j.nedt. 2013.08 .013

[11] Kantar LD, Massouh A. Case-based learning: What traditional curricula fail to teach. Nurse Education Today. 2015; 35(8): 8 14. PMid:25842004 http://dx.doi.org/10.1016/j.nedt. 20 15.03 .010

[12] Koch LF. The nursing educator's role in e-learning: A literature review. Nurse Education Today. 2014; 34(11): 1382-7. PMid:24797277 http://dx.doi.org/10.1016/j.nedt. 2014.04.002

[13] Ramm D, Thomson A, Jackson A. Learning clinical skills in the simulation suite: The lived experiences of student nurses involved in peer teaching and peer assessment. Nurse Education Today. 2015; 35(6): 823-7. PMid:25697946 http://dx.doi.org/10.1016/j .nedt.2015.01.023
$\mathrm{CNO}$ and Dr. Mae Squires, professor and associate dean of the School of Baccalaureate Nursing, St. Lawrence College for reviewing the manuscript.

\section{CONFLicts OF InTEREST Disclosure}

The authors declare that there is no conflict of interest.
[14] Reid Searl K, McAllister M, Dwyer T, et al. Little people, big lessons: An innovative strategy to develop interpersonal skills in undergraduate nursing students. Nurse Education Today. 2014; 34(9): 1201-6. PMid:24844763 http://dx.doi.org/10.1016/j.nedt. 2014.04 .004

[15] Naber J, Wyatt TH. The effect of reflective writing interventions on the critical thinking skills and dispositions of baccalaureate nursing students. Nurse Education Today. 2014; 34(1): 6772. PMid:23623746 http://dx.doi.org/10.1016/j.nedt. 20 13.04 .002

[16] Spiers JA, Paul P. Strategies for Engaging Undergraduate Nursing Students in Reading and Using Qualitative Research. The Qualitative Report. 2012; 17(Art. 48): 1-22. Available from: http: //www.nova.edu/ssss/QR/QR17/spiers.pdf

[17] Hemman EA, Fought SG. Teaching undergraduate nurses nursing phenomena. Nurse Education. 2010; 35(1): 25-8. PMid:20010266 http://dx.doi.org/10.1097/NNE.0b013e3181c420f8

[18] Carolan-Olah M, Kruger G. Final year students' learning experiences of the Bachelor of Midwifery course. Midwifery. 2014; 30(8): 95661. PMid:23938164 http://dx.doi.org/10.1016/j .midw . 20 13.07 .010

[19] Knecht JG, Fischer B. Undergraduate nursing students' experience of service-learning: A phenomenological study. Journal of Nursing Education. 2015; 54(7): 378-84. PMid:26155029 http: //dx.doi.org/10.3928/01484834-20150617-04

[20] Blomberg K, Bisholt B. Clinical group supervision for integrating ethical reasoning: Views from students and supervisors. Nurse Ethics. 2015.

[21] Queen's University. Faculty of Health Science. [cited 2015 Nov 22]. Available from: http://healthsci.queensu.ca/liscbchm/li fe_sciences/alumni

[22] Brownell SE, Kloser MJ. Toward a conceptual framework for measuring the effectiveness of course-based undergraduate research experiences in undergraduate biology. Studies High Educ. 2015; 40(3): 52544. http://dx. doi .org/10.1080/03075079. 2015.1004234

[23] Allyn DA. Course-based Undergraduate Research-It Can Be Accomplished! Journal of Physical Education. 2013; 84(9): 32-6. http://dx.doi.org/10.1080/07303084.2013.838113

[24] Brownell SE, Hekmat-Scafe DS, Singla V, et al. A High-Enrollment Course-Based Undergraduate Research Experience Improves Student Conceptions of Scientific Thinking and Ability to Interpret Data. CBE Life Sci Educ. 2015; 14(2): ar21. PMid:26033869 http://dx.doi.org/10.1187/cbe.14-05-0092

[25] Linn MC, Palmer E, Baranger A, et al. Undergraduate research experiences: Impacts and opportunities. Science. 2015; 347(6222). PMid:25657254 http://dx.doi.org/10.1126/sci ence. 1261757

[26] Laurie G. Researching the Conflicts: Undergraduate Research and the Introductory Literature Curriculum Teaching English in the Two Year College (37:4). 2010. 372-383. 